\title{
How to perform the dusting technique for calcium oxalate stone phantoms during Ho:YAG laser lithotripsy
}

\author{
Jeong Woo Lee ${ }^{1}$, Min Gu Park² and Sung Yong Cho ${ }^{3^{*}}$
}

\begin{abstract}
Background: To determine the most efficacious setting of Holmium:yttrium-aluminum-garnet (Ho:YAG) laser with a maximum power output of $120 \mathrm{~W}$ with in vitro phantom-stone dusting technique.

Methods: A laser was used to treat two $4 \times 3 \times 3 \mathrm{~mm}^{3}$ sized phantom stones in $5 \mathrm{~mL}$ syringes with $1 \mathrm{~mm}$-sized holes at the bottom. According to the pulse width (short 500, middle 750, long pulse $1000 \mu \mathrm{sec}$ ), maximal pulse repetition rates from 50 to $80 \mathrm{~Hz}$ were tested with pulse energy of $0.2,0.4,0.5$, and $0.8 \mathrm{~J}$. Six times of the mean dusting times were measured at each setting. Dusting was performed at continuous firing of the laser until the stones become dusts $<1 \mathrm{~mm}$.

Results: The mean Hounsfield unit of phantom stones was $1309.0 \pm 60.8$. The laser with long pulse generally showed shorter dusting times than short or middle pulse width. With increasing the pulse energy to $0.5 \mathrm{~J}$, the dusting time decreased. However, the pulse energy of $0.8 \mathrm{~J}$ showed longer dusting times than those of $0.5 \mathrm{~J}$. On the post-hoc analysis, the pulse energy of $0.5 \mathrm{~J}$, long pulse width, and the repetition rates of $70 \mathrm{~Hz}$ demonstrated significantly shorter dusting times than other settings.
\end{abstract}

Conclusions: The results suggest that long pulse width with $0.5 \mathrm{~J}$ and $70 \mathrm{~Hz}$ would be the most efficacious setting for dusting techniques of plaster stone phantoms simulating calcium oxalate stones using the $120 \mathrm{~W}$ Ho:YAG laser.

Keywords: Calcium oxalate, Dusting, Energy, Ho:YAG laser, Lithotripsy

\section{Background}

Laser lithotripsy has remained the first-line treatment option for urinary stones with technical advancements in dedicated endoscopes, instruments, and accessories [1-3]. Recent investigations demonstrated high success rates and low complication rates of the minimally invasive surgical techniques using the Holmium:yttrium-aluminum-garnet (Ho:YAG) laser, especially in miniaturized percutaneous nephrolithotomy and retrograde intrarenal surgery [4-7]. The pulsed Ho:YAG laser has become one of the main lithotripters along with the ultrasonic or pneumatic lithotripter [2].

Laser efficacy during lithotripsy is essential to obtain the maximal surgical efficacy and excellent surgical outcome.

\footnotetext{
*Correspondence: kmoretry@daum.net

${ }^{3}$ Department of Urology, Seoul Metropolitan Government-Seoul National University Boramae Medical Center, Seoul National University College of Medicine, 20, Boramae-ro 5-Gil, Dongjak-gu, Seoul 156-707, Republic of Korea Full list of author information is available at the end of the article
}

The efficacy of Ho:YAG laser-mediated stone fragmentation is better with increased energy per pulse and reduced pulse width, but not consistently with pulse repetition rates with a power output of $10 \sim 20 \mathrm{~W}$ [8-10]. Meanwhile, stone dusting with low pulse energy and high pulse repetition rates reduces the size of fragmented stones until they become dusts, which improves stone clearance [8]. This is because the Ho:YAG laser produces less retropulsion from the fiber tip in the lower power energy, which affects the surgical efficacy.

The recent development of the high-power output $120 \mathrm{~W}$ Ho:YAG laser system has provided surgeons with additional options for stone dusting, courtesy of increased pulse repetition rates from 50 to $80 \mathrm{~Hz}$ and three different options of pulse width from 500 to $1000 \mu \mathrm{sec}$. However, there is no consensus of the optimal laser setting for stone dusting. To provide clarity, we investigated the impact of pulse energy, width, and 
repetition rates on the dusting efficacy of phantom stones in vitro using the $120 \mathrm{~W}$ Ho:YAG laser system. The aim was to determine the most efficacious laser setting for stone dusting.

\section{Methods}

The authors sought to determine the influence on the dusting efficacy according to each setting value of the hand-held optical fiber of Ho:YAG laser pulse energy (pulse width) and the repetition rate based on each pulse width.

\section{Laser system and parameters}

The experiments were performed using a $2.1 \mu \mathrm{m}$ emitting Lumenis VersaPulse PowerSuite Holmium (Ho:YAG) surgical laser $120 \mathrm{H}^{\circ}$ (Lumenis Ltd., Israel) with a maximum power output of $120 \mathrm{~W}$ for fibers with core diameters of $200 \mu \mathrm{m}$. Pulse widths were short $(500 \mu \mathrm{sec})$, middle $(750 \mu \mathrm{sec})$, and long $(1000 \mu \mathrm{sec})$. The maximal pulse repetition rates were 50,70 , and $80 \mathrm{~Hz}$. The pulse energies were $0.2,0.4,0.5$, and $0.8 \mathrm{~J}$. The maximal repetition rates differed according to the pulse width and pulse energy.

\section{Stone sample preparation}

The molded plaster phantom stones were obtained from SINI Inc. (Ui-Wang, Gyeonggi-do, Korea) (Fig. 1). The stone density mimics the hardness of human calcium oxalate monohydrate calculi, consistent with a prior study [4]. Two calculi were used for each laser experiment. The stone size was cut up into equal cubical pieces of $4 \times 3 \times 3 \mathrm{~mm}^{3}$.

\section{Hand-held dusting techniques}

Only freshly cleaved $200 \mu \mathrm{m}$ fibers were used. The fiber tip was positioned 1 to $2 \mathrm{~mm}$ from the phantom stone by the investigator (Cho SY). The $5 \mathrm{ml}$ syringes had a $1 \mathrm{~mm}$-sized hole at the bottom where stone dust exited the syringe into a pan (Fig. 2). The irrigation pressure was set to $40 \mathrm{cmH}_{2} \mathrm{O}$ from the phantom stones. Dusting was performed with continuous firing of the laser until the stones became a dust with a particle size $<1 \mathrm{~mm}$. The dusting time was defined from the initiation of laser firing to the formation of this dust.

\section{Statistical analyses}

All parameters represented the mean value \pm standard deviation (percentage). Comparative results were analyzed using independent $\mathrm{t}$-test or Mann-Whitney $\mathrm{U}$ test between the two groups and Kruskal-Wallis test among the groups. Post-hoc analysis with Tukey's honestly significant difference test was performed. Categorical variables were analyzed by Chi-square and Fisher's exact test. Statistical significance was considered at $P<.05$. Statistical analyses were performed by the statistical software SPSS version 20 (IBM, Armonk, NY) and R version 3.0.1 (http://www.r-project.org).

\section{Results}

The mean Hounsfield unit was $1309.0 \pm 60.8$. The mean dusting time was determined from six measurements of each study criterion given. The results are summarized in Table 1. The highest repetition rate was $70 \mathrm{~Hz}$ with long and middle pulse widths and pulse energies of 0.2 , 0.4 , and $0.5 \mathrm{~J}$, and $80 \mathrm{~Hz}$ with short pulse width and pulse energies from 0.2 to $0.5 \mathrm{~J}$. The highest repetition

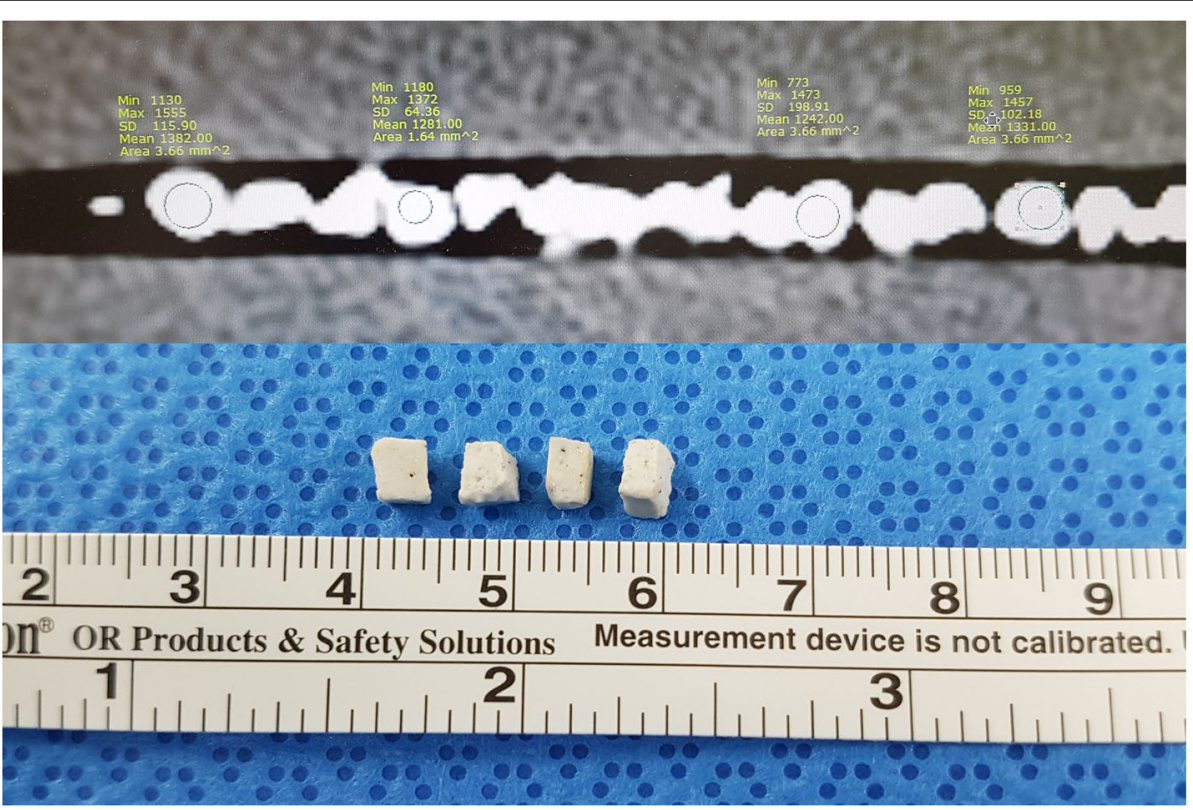

Fig. 1 a Stone density measured in the computed tomography scan images. $\mathbf{b}$ Each cubical stone of $4 \times 3 \times 3 \mathrm{~mm}^{3}$ 


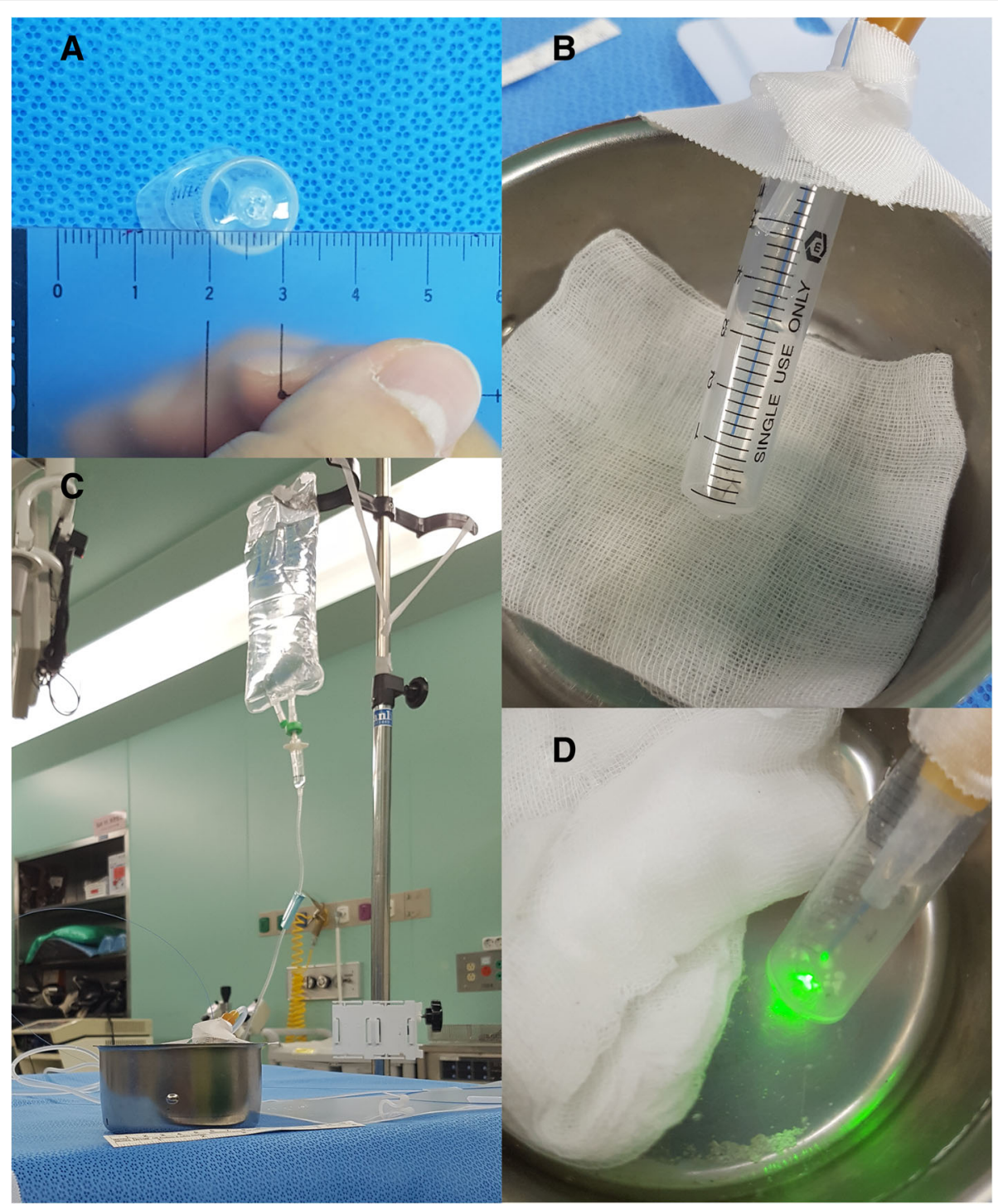

Fig. 2 a A 1 mm-sized hole at the bottom of the syringe for fragmented particles to go out. b A laser fiber was positioned 1-2 mm away from the phantom stones when the dusting technique starts. $\mathbf{c}$ Irrigation fluid at the height of $40 \mathrm{cmH}_{2} \mathrm{O}$ to mimic the real practice situation. $\mathbf{d}$ Dusts $<1 \mathrm{~mm}$ went out of the syringe during laser firing. When the all particles disappear in the syringe, the duration of dusting was checked by a stop-watch

rate was $50 \mathrm{~Hz}$ for $0.8 \mathrm{~J}$ of pulse energy for each pulse width.

The long pulse width generally produced shorter dusting times than short or middle pulse widths. As the pulse energy increased to $0.5 \mathrm{~J}$, the dusting time decreased. However, the pulse energy of $0.8 \mathrm{~J}$ produced a longer dusting time than pulse energy of $0.5 \mathrm{~J}$.

Figure 3 depicts results of a post-hoc analysis of the mean dusting time measured at each setting. Pulse energy of $0.5 \mathrm{~J}$, a long pulse width, and a repetition rate of $70 \mathrm{~Hz}$ proved to be the most efficacious dusting setting (Group A). Group B included pulse energy of $0.5 \mathrm{~J}$ (middle and short pulse widths) and $0.4 \mathrm{~J}$ or $0.8 \mathrm{~J}$ (long pulse width). Group $\mathrm{C}$ included pulse energies of $0.4 \mathrm{~J}$ and $0.8 \mathrm{~J}$ with middle or short pulse width. Group D comprised pulse energy of $0.2 \mathrm{~J}$ regardless of pulse width and repetition rate.

\section{Discussion}

The pulsed Ho:YAG laser is used predominantly with flexible ureterorenoscopic and miniaturized percutaneous devices. This laser has become the preferred lithotripter in clinical use over the past two decades [2]. The maximal efficacy of laser lithotripsy techniques, mainly stone fragmentation and dusting, are essential to improve surgical outcomes. The efficacy of lithotripsy obtained using the Ho:YAG laser depends on laser settings that include energy per pulse, pulse width, and pulse repetition rates [8]. Factors that favor the fragmentation 
Table 1 Dusting time (sec) according to each laser setting

\begin{tabular}{|c|c|c|c|c|c|c|c|c|c|c|c|c|}
\hline \multirow{2}{*}{$\frac{\text { Dusting time (sec) }}{\text { Short pulse }}$} & \multirow{2}{*}{$\frac{\mathrm{Hz}}{80}$} & \multirow{2}{*}{$\frac{\text { Test }}{1}$} & \multirow{2}{*}{$\frac{0.2 \mathrm{~J}}{1120}$} & \multicolumn{2}{|l|}{$\mathrm{Hz}$} & \multirow{2}{*}{$\begin{array}{l}0.4 \mathrm{~J} \\
720\end{array}$} & \multicolumn{2}{|l|}{$\mathrm{Hz}$} & \multirow{2}{*}{$\frac{0.5 \mathrm{~J}}{540}$} & \multicolumn{2}{|l|}{$\mathrm{Hz}$} & \multirow{2}{*}{$\frac{0.8 \mathrm{~J}}{600}$} \\
\hline & & & & 80 & 1 & & 80 & 1 & & 50 & 1 & \\
\hline & & 2 & 1080 & & 2 & 800 & & 2 & 660 & & 2 & 780 \\
\hline & & 3 & 1560 & & 3 & 750 & & 3 & 900 & & 3 & 720 \\
\hline & & 4 & 1440 & & 4 & 960 & & 4 & 540 & & 4 & 910 \\
\hline & & 5 & 1350 & & 5 & 1000 & & 5 & 600 & & 5 & 800 \\
\hline & & 6 & 1470 & & 6 & 750 & & 6 & 580 & & 6 & 760 \\
\hline & \multicolumn{2}{|c|}{ Mean \pm S.D } & $1336.7 \pm 195.6$ & \multicolumn{2}{|c|}{ Mean \pm S.D } & $830.0 \pm 119.7$ & \multicolumn{2}{|c|}{ Mean \pm S.D } & $636.7 \pm 136.5$ & \multicolumn{2}{|c|}{ Mean \pm S.D } & $761.7 \pm 101.7$ \\
\hline \multirow[t]{7}{*}{ Middle pulse } & \multirow[t]{6}{*}{70} & 1 & 1140 & \multirow[t]{6}{*}{70} & 1 & 780 & \multirow[t]{6}{*}{70} & 1 & 360 & \multirow[t]{6}{*}{50} & 1 & 780 \\
\hline & & 2 & 1250 & & 2 & 900 & & 2 & 480 & & 2 & 700 \\
\hline & & 3 & 1080 & & 3 & 820 & & 3 & 400 & & 3 & 650 \\
\hline & & 4 & 1360 & & 4 & 990 & & 4 & 500 & & 4 & 660 \\
\hline & & 5 & 1240 & & 5 & 800 & & 5 & 420 & & 5 & 590 \\
\hline & & 6 & 1180 & & 6 & 700 & & 6 & 410 & & 6 & 660 \\
\hline & \multicolumn{2}{|c|}{ Mean $\pm S . D$} & $1208.3 \pm 97.7$ & \multicolumn{2}{|c|}{ Mean \pm S.D } & $831.7 \pm 100.9$ & \multicolumn{2}{|c|}{ Mean \pm S.D } & $428.3 \pm 52.3$ & \multicolumn{2}{|c|}{ Mean \pm S.D } & $673.3 \pm 63.1$ \\
\hline \multirow[t]{7}{*}{ Long pulse } & \multirow[t]{6}{*}{70} & 1 & 1140 & \multirow[t]{6}{*}{70} & 1 & 540 & \multirow[t]{6}{*}{70} & 1 & 300 & \multirow[t]{6}{*}{50} & 1 & 540 \\
\hline & & 2 & 1260 & & 2 & 600 & & 2 & 350 & & 2 & 500 \\
\hline & & 3 & 1050 & & 3 & 480 & & 3 & 280 & & 3 & 620 \\
\hline & & 4 & 1300 & & 4 & 580 & & 4 & 320 & & 4 & 600 \\
\hline & & 5 & 1220 & & 5 & 600 & & 5 & 350 & & 5 & 500 \\
\hline & & 6 & 1200 & & 6 & 900 & & 6 & 300 & & 6 & 480 \\
\hline & \multicolumn{2}{|c|}{ Mean \pm S.D } & $1195.0 \pm 89.4$ & \multicolumn{2}{|c|}{ Mean \pm S.D } & $616.7 \pm 146.1$ & \multicolumn{2}{|c|}{ Mean \pm S.D } & $316.7 \pm 28.8$ & \multicolumn{2}{|c|}{ Mean \pm S.D } & $540.0 \pm 58.0$ \\
\hline
\end{tabular}

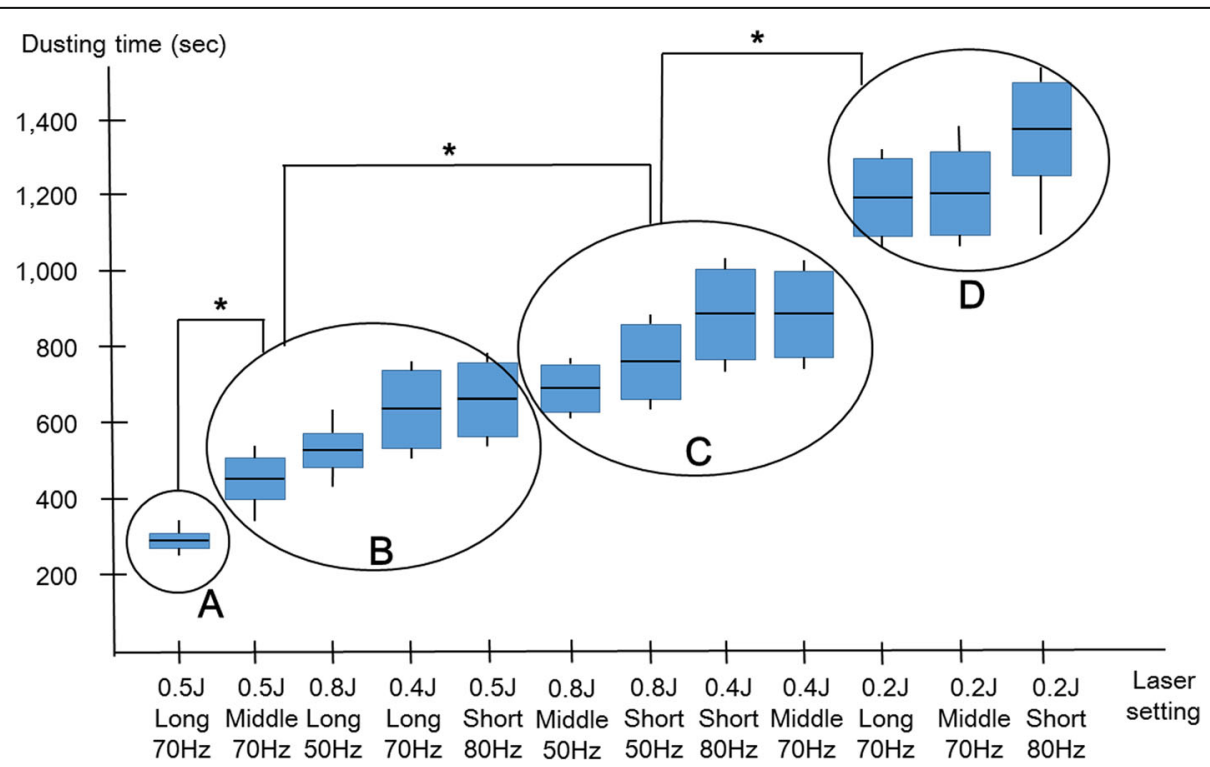

Fig. 3 Post-hoc analysis to compare the mean dusting time per each setting and across the groups a (0.5 J, a long pulse width, and $70 \mathrm{~Hz}$ ), b (0.5 J (middle and short pulse widths), c (0.4 and $0.8 \mathrm{~J}$, middle or short pulse width), and d (0.2 J groups) 
efficacy of the Ho:YAG laser with a power output of 10 $20 \mathrm{~W}$ are increased pulse energy and reduced pulse width [8-10]. Stone dusting is a recently established outcome of Ho:YAG laser use. Dusting is routinely performed with a low pulse energy and high pulse repetition rate to obtain maximum stone clearance. A Ho:YAG laser system with a maximum power output of $120 \mathrm{~W}$ was recently developed, which enables the surgeon to choose increased pulse repetition rates of $50 \mathrm{~Hz}$ or $80 \mathrm{~Hz}$ according to the pulse energy. Additionally, this new device has three different options of pulse width (short, middle, and long pulse of 500, 750, and $1000 \mu$ sec, respectively). Few investigations have assessed the optimal settings of this laser system. The present study involving in vitro reproducible experiments with phantom stones was done to define the most efficient laser setting for stone dusting.

The ideal for stone dusting during Ho:YAG lithotripsy is to use a setting that produces maximal fragmentation efficacy. The aim is to transform stone fragments into dust particles $<1 \mathrm{~mm}$ in size. Previous investigations explored the effect of various pulse energy of the Ho:YAG laser for stone fragmentation [11-13]. Increased pulse energy increases fragmentation power but increases retropulsion for the fragmented stones. Increased retropulsion may induce less energy transmission to stones and lower repetition rates, which may result in less fragmentation efficacy [14]. Low pulse energy $(0.2 \mathrm{~J})$ produces small fragment debris and less retropulsion at a slower fragmentation rate [11]. Presently, a pulse energy of $0.5 \mathrm{~J}$ and $70 \mathrm{~Hz}$ repetition rate with a long pulse was the most appropriate setting for stone dusting of plaster stones representing calcium oxalate monohydrate stones. This may be because retropulsion is significant in determining stone dusting efficacy. A low pulse energy of 0.2 or $0.4 \mathrm{~J}$ may be not efficacious to fragment phantom stones with a mean Hounsfield unit of 1309.0.

The association between pulse width and stone fragmentation efficacy has been studied in vitro $[8,9$,

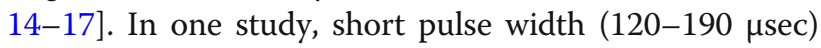
produced equivalent fragmentation effectiveness, but more retropulsion compared to long pulse width (210$350 \mu \mathrm{sec})$ [15]. A ureter and caliceal model was used to demonstrate that a pulse width of $700 \mu$ sec provided less retropulsion and more effective stone fragmentation compared to a pulse width of $350 \mu \mathrm{sec}$ [14]. In contrast, in an in vitro impacted and immobile phantom stones model, reduction of the pulse width from 700 to $350 \mu$ sec increased the fragmentation effectiveness of a Ho:YAG system with $10 \mathrm{~W}$ power [9]. In the present study, the mean dusting time decreased with increasing pulse width from 500 to $1000 \mu \mathrm{sec}$. The long pulse width $(1000 \mu \mathrm{sec})$ provided the most effective stone dusting at a pulse energy $\geq 0.4 \mathrm{~J}$.
Pulse repetition rates may not be critical to fragmentation efficacy $[10,11]$. In these studies, the mean dusting time did not differ significantly at a pulse repetition rate of 70 and $80 \mathrm{~Hz}$. These findings support the view that energy per pulse and pulse width, rather than pulse repetition rate, are more closely associated with stone fragmentation and stone dusting.

The present results might support the following 'ideal' settings of the Ho:YAG laser in stone dusting. The energy should be as low as possible to minimize retropulsion, while being powerful enough to break down the targeted stones. A longer pulse width is better than a shorter width. Higher repetition rates may be better than the lower ones.

Evidence about the dusting efficacy during stone surgery with the $120 \mathrm{~W}$ Ho:YAG laser system is limited. During laser lithotripsy, dusting technique usually needs the laser setting of low-pulse energy and high frequency [18]. A recent investigation assessed surgical outcomes of dusting technique in 82 renal units of 71 patients utilizing $120 \mathrm{~W}$ Ho:YAG laser with $200-\mu \mathrm{m}$ fibers [19]. The mean stone size was $12.5 \pm 8.7 \mathrm{~mm}$ and the mean Hounsfield unit was $993 \pm 353$. The laser setting for hard stones (> $1000 \mathrm{HU}$ ) during dusting technique was pulse energy of $0.3 \mathrm{~J}, 70 \mathrm{~Hz}$ repetition rates and short pulse width mode. For soft stones $(<1000 \mathrm{HU})$, the laser setting was pulse energy of $0.2 \mathrm{~J}, 80 \mathrm{~Hz}$ repetition rates and short pulse width mode. Although there were no direct comparative results between short and long pulse width modes, the complete stone free rate was $39 \%$ and < $2 \mathrm{~mm}$ residual fragments were identified in $69 \%$. Another important point is the heat generation during laser lithotripsy. There have been few studies on thermal effects in terms of injury to adjacent organs during dusting technique with the $120 \mathrm{~W}$ Ho:YAG laser system. The authors did not measure fluid temperature during continuous firing of the laser. However, continuous irrigation with cool normal sline prevented overgeneration of heat during experiments. Further laboratory studies or clinical trials are needed to confirm the most efficacious and safe setting for dusting technique with the $120 \mathrm{~W}$ Ho:YAG laser system.

This study has some limitations. The experiments were not performed to mimic minor calyces of the human kidneys. So, the results do not reflect the situation in which a fragmented stone might migrate from one to another calyx. Phantom stones were previously reported to provide an adequate model to evaluate efficacy of stone fragmentation and retropulsion of Ho:YAG laser setting [8-17]. The authors used a single kind of phantom stone, which mimicked human calcium oxalate monohydrate calculi. The optimal stone fragmentation can be achieved according to helical/snail schema and the present study could not show the effect of stone 
retropulsion. In addition, only straightened laser fibers of $200 \mu \mathrm{m}$ were used. Further studies are needed to determine the appropriate laser settings for other clinically possible situations including different kinds of stones.

\section{Conclusions}

In vitro reproducible experiments with phantom stones mimicking calcium oxalate monohydrate calculi demonstrates that a pulse energy of $0.5 \mathrm{~J}$, long pulse width, and a repetition rate of $70 \mathrm{~Hz}$ provides the most efficacious dusting with the high-power output $120 \mathrm{~W}$ Ho:YAG laser in combination with a 200- $\mu \mathrm{m}$ fiber. The findings do not apply to other types of human calculi, but still have value in clinical practice.

\section{Abbreviation}

Ho:YAG: Holmium:yttrium-aluminum-garnet

\section{Acknowledgements}

None.

\section{Funding}

This research was supported by the Materials and Components Technology Development Program of MOTIE/KEIT, Republic of Korea (10067258, Development of a holmium/thulium laser resonator for treatment of prostatic hyperplasia).

\section{Availability of data and materials}

All data generated or analysed during this study are included in this published article.

\section{Authors' contributions \\ LJW: analysis and interpretation of data, statistical analysis, drafting of the manuscript. PMG: conception and design, acquisition of data, supervision. CSY: conception and design, acquision of data, obtaining funding, administrative, technical, or material support, supervision. All authors read and approved the final manuscript.}

\section{Ethics approval and consent to participate}

This paper is not associated with research involving human subjects, human material, or human data. As such, not ethical approval was required.

\section{Consent for publication}

None.

\section{Competing interests}

The authors declare that they have no competing interests.

\section{Publisher's Note}

Springer Nature remains neutral with regard to jurisdictional claims in published maps and institutional affiliations.

\section{Author details}

'Department of Urology, Dongguk University Ilsan Hospital, Dongguk University College of Medicine, 27, Dongguk-ro, Ilsandong-gu, Goyang-si, Gyeonggi-do 410-773, Republic of Korea. 'Department of Urology, Seoul Paik Hospital, Inje University College of Medicine, 9, Mareunnae-ro, Jung-gu, Seoul 100-032, Republic of Korea. ${ }^{3}$ Department of Urology, Seoul Metropolitan Government-Seoul National University Boramae Medical Center, Seoul National University College of Medicine, 20, Boramae-ro 5-Gil, Dongjak-gu, Seoul 156-707, Republic of Korea.
Received: 6 July 2017 Accepted: 30 October 2018

Published online: 13 November 2018

References

1. Bader MJ, Eisner B, Porpiglia F, Preminger GM, Tiselius HG. Contemporary management of ureter stones. Eur Urol. 2012;61:764-72.

2. Blackmon RL, Irby PB, Fried NM. Comparison of holmium:YAG and thulium fiber laser lithotripsy: ablation thresholds, ablation rates, and retropulsion effects. J Biomed Opt. 2011;16:071403.

3. Lee SH, Kim TH, Myung SC, et al. Effectiveness of flexible ureteroscopic stone removal for treating ureteral and ipsilateral renal stones: a singlecenter experience. Korean J Urol. 2013;54:377-82.

4. Lee JW, Park J, Lee SB, Son H, Cho SY, Jeong H. Mini-percutaneous nephrolithotomy vs retrograde intrarenal surgery for renal stones larger than $10 \mathrm{~mm}$ : a prospective randomized controlled trial. Urology. 2015;86:873-7.

5. Kumar A, Kumar N, Vasudeva P, Kumar Jha S, Kumar R, Singh H. A prospective, randomized comparison of shock wave lithotripsy, retrograde intrarenal surgery and miniperc for treatment of 1 to $2 \mathrm{~cm}$ radiolucent lower calyceal calculi: a single center experience. J Urol. 2015;193:160-4.

6. Kirac M, Bozkurt ÖF, Tunc L, Guneri C, Unsal A, Biri H. Comparison of retrograde intrarenal surgery and mini-percutaneous nephrolithotomy in management of lower-pole renal stones with a diameter of smaller than 15 mm. Urolithiasis. 2013;41:241-6.

7. Sabnis RB, Jagtap J, Mishra S, Desai M. Treating renal calculi $1-2 \mathrm{~cm}$ in diameter with minipercutaneous or retrograde intrarenal surgery: a prospective comparative study. BJU Int. 2012;110:E346-9.

8. Bader MJ, Pongratz T, Khoder W, et al. Impact of pulse duration on ho:YAG laser lithotripsy: fragmentation and dusting performance. World J Urol. 2015; 33:471-7.

9. Wezel F, Häcker A, Gross AJ, Michel MS, Bach T. Effect of pulse energy, frequency and length on holmium:yttrium-aluminum-garnet laser fragmentation efficiency in non-floating artificial urinary calculi. J Endourol. 2010:24:1135-40.

10. Chawla SN, Change MF, Chang A, Lenoir J, Bagley DH. Effectiveness of highfrequency holmium:YAG laser stone fragmentation: the "popcorn effect". J Endourol. 2008;22:645-50.

11. Sea J, Jonat LM, Chew BH, et al. Optimal power settings for holmium:YAG lithotripsy. J Urol. 2012;187:914-9.

12. Spore SS, Teichman JM, Corbin NS, Champion PC, Williamson EA, Glickman RD. Holimium: YAG lithotripasy: optimal power settings. J Endourol. 1999;13:559-66.

13. Corbin NS, Teichman JM, Nguyen T, et al. Laser lithotripsy and cyanide. J Endourol. 2000;14:169-73.

14. Finley DS, Petersen J, Abdelshehid C, et al. Effect of holmium:YAG laser pulse width on lithotripsy retropulsion in vitro. J Endourol. 2005;19:1041-4.

15. Kang HW, Lee H, Teichman JM, Oh J, Kim J, Welch AJ. Dependence of calculus retropulsion on pulse duration during Ho: YAG laser lithotripsy. Lasers Surg Med. 2006:38:762-72.

16. Lee HJ, Box GN, Abraham JB, et al. In vitro evaluation of nitinol urological retrieval coli and ureteral occlusion device: retropulsion and holmium laser fragmentation efficiency. J Urol. 2008;180:969-73.

17. Marguet CG, Sung JC, Springhart WP, et al. In vitro comparison of stone retropulsion and fragmentation of the frequency doubled, double pulse nd: yag laser and the holmium:yag laser. J Urol. 2005;173:1797-800.

18. Patel AP, Knudsen BE. Optimizing use of the holmium:YAG laser for surgical management of urinary lithiasis. Curr Urol Rep. 2014;15:397.

19. Tracey J, Gagin G, Morhardt D, Hollingsworth J, Ghani KR. Ureteroscopic high-frequency dusting utilizing a 120-W holmium laser. J Endourol. 2018; 32:290-5. 